\title{
Experimental study on heat and mass transfer of falling liquid films in converging-diverging tubes with water
}

\author{
Kuo Huang ${ }^{1,2 *}$, Yukun $\mathrm{Hu}^{3}$, Xianhe Deng ${ }^{1 *}$ \\ ${ }^{1}$ Department of Chemistry and Chemical Engineering, South China University of Technology, \\ Guangzhou, Guangdong 510640, People's Republic of China \\ ${ }^{2}$ Guangzhou Institute of Energy Testing, Guangzhou, Guangdong 511447, People's Republic of \\ China \\ ${ }^{3}$ Complex System Research Centre, Cranfield University, Bedford MK43 0AL, United Kingdom
}

\begin{abstract}
To improve the heat and mass transfer performances of falling films and develop a new type of falling film evaporator, the characteristics of falling film evaporation and sensible heat and mass transfer in four different sizes of converging-diverging (CD) tubes were experimentally explored in this study. By analyzing the relationship between the heat transfer coefficient and the falling film flow rate, it was found that the $\mathrm{CD}$ tube is suitable for falling film evaporation and sensible heating with a large Reynolds number. For different sizes of tubes, the key factor affecting the heat transfer in falling film evaporation and sensible heating is the height of the ribs. At the same rib height and rib pitch, the longer the converging segment of the CD tube, the better the heat transfer performance. According to the comparative analysis of the evaporation and sensible heating heat transfer performances inside the four $\mathrm{CD}$ tubes, the $\mathrm{CD}$ tube $3 \#$ is best. The evaporation heat transfer coefficient (at Reynolds number of liquid films of 2356), evaporation mass transfer rate (at the perimeter flow rate of liquid films is $0.173 \mathrm{kgm}^{-1} \mathrm{~s}^{-1}$ ), and sensible heating heat transfer coefficient (at Reynolds number of liquid films of 1635) of CD tube $3 \#$ are $62 \%, 38 \%$ and $63 \%$ higher than that of the smooth tube, respectively. For the same $\mathrm{CD}$ tube, the evaporation heat transfer coefficient is larger than the sensible heating heat transfer coefficient, but both increases as the flow rate increases. The heat transfer correlations of falling film evaporation and sensible heating in the experimental range were obtained through data fitting. It will provide a useful reference for future engineering design and industrial applications.
\end{abstract}


Keywords: Converging-diverging tube; Falling liquid films; Heat transfer; Mass transfer

\section{Introduction}

The heat and mass transfer of the falling film flowing over a vertical heating surface is of great importance in many industrial operations, such as the temperature raise or evaporation of the liquid, or selective evaporation of specific components. Such operation, that is falling film evaporator, has been widely used in seawater desalination, pulp and paper, food processing, air-conditioning and many other industries [1]. With the rapid economic and social development, rising energy prices, and increasing environmental protection requirements, the industrial demand for energy-consuming equipment continues to rise. Therefore, the development of enhanced heat and mass transfer technology that can improves the heat transfer performance of the falling film evaporator and increase its evaporation efficiency is of great significance to the project investment, energy saving and consumption reduction.

Much research has been conducted from different influencing factors on falling film heat transfer of vertical smooth tubes, see, e.g. Refs. [2-6], regarding flow regimes, [7-9] for liquids properties, [10] for liquid film surface tension, [11-13] for phase shear stress, and [14-15] for thermal entry length. For literature concerning different influencing factors, it is common knowledge that flow regimes exert the most pronounced influence on heat transfer $[7,16]$. However, it is rarely on the heat transfer enhancement of vertical smooth tubes, and the major existing enhancement methods include tube gas ventilation, tube insertion, and tube shape modification. In the existing enhancement methods, tube shape modification was more studied. For example, Fagerholm et al. [17] used four enhanced heat transfer tubes (High flux, Gewa-T, Thermoexcel-E and-EC) to perform the falling film evaporation experiments, respectively, and found that the four enhanced heat transfer tubes can improve the heat transfer performance. Park and Choi [18] used a vertical grooved tube to study 
the coupled evaporation and condensation processes of the downwardly flowing film along the inner and outer walls of the tube and demonstrated how the grooved surface enhances heat transfer. Jiang [19] used corrugated tubes to divert the liquid film to flow downwards along alternant curves and to thin the turbulent boundary layer through flow speeds. The results showed that the heat transfer performance was improved by about $10 \%$. Pehlivan [20] studied the heat transfer characteristic of air flow in corrugated channels, and found that the increase of corrugated angle and channel height tends to increase heat transfer. Gonda et al. [21] experimentally studied the falling film evaporation on a single vertical corrugated plate, and found the heat transfer coefficient was at least 50\% higher than the smooth plate. Fan et al. [22] studied the effect of the inner surface sintered porous tube on the heat transfer of falling film evaporation, and found that its heat transfer coefficient and total heat transfer coefficient were $103 \%$ and $78 \%$ larger than that of the smooth tube. However, due to the difficulties in manufacturing and maintenance, many enhanced heat transfer tubes have not been extensively applied in the industry.

The development and application of high efficiency enhanced heat transfer units have been the most active and vital research topic in the field of heat and mass transfer. Converging-diverging (CD) tube is a typical enhanced heat transfer tube, consisting of alternating divergence and convergence segments. In the case of higher heat transfer coefficient, smoother surface transition, and smaller flow resistance, the CD tube is widely applied in sulfuric acid, petrochemical and other industries [23-24]. The enhanced heat transfer in CD tubes has been extensively studied [25-26], which consistently indicate CD tubes have better enhanced heat transfer performance. Our previous research has accumulated a lot of experimental data about the CD tube. For example, Zhang et al. [27-28] used CD tubes for natural convection heat transfer and natural convection boiling heat transfer experiments and the results showed that the heat transfer coefficients were improved to some extent compared with the smooth tube. Chen et al. [29-30] studied the turbulence convection heat transfer in CD tubes through numerical simulations and revealed the distribution laws of flow-direction field synergy that affecting the convective heat transfer intensity. Besides, based on 
the optimized CD tube proposed by Мигай [31], an improved structure of the CD tube was put forward by extending the length of converging segment and shortening the length of the diverging segment, and they demonstrated its higher heat transfer coefficient than common CD tube. Huang et al. [32-33] studied the mechanism of enhanced heat transfer in $\mathrm{CD}$ tubes and found that the key parameter affecting the heat transfer performance - roughness height should be located in the flow transition zone. Meanwhile, Duryodhan [34] carried out single phase fluid flow and heat transfer in diverging and converging microchannels, and found that the heat transfer coefficient is $35 \%$ higher in converging microchannel compared with diverging microchannel. Currently, the research on CD tubes as high-efficiency enhanced heat transfer units mainly focuses on single-phase flow and convective boiling heat transfer inside and outside the tube, but rarely focuses on falling film evaporation or sensible heating. In this study, to improve the heat and mass transfer performance of the falling film and develop a new type of falling film evaporator using water as a working fluid, the characteristics of falling film evaporation and sensible heat and mass transfer in four different sizes of CD tubes were experimentally explored and compared with the smooth tube. In the literature mentioned above, there are many influencing factors on falling film heat transfer. However, this work mainly focuses on the effect of the liquid film flow rate on the heat transfer coefficient. The findings together with the analysis of the enhanced heat and mass transfer performances of falling film evaporation and sensible heating forms the basis for applying CD tubes to falling film evaporators.

\section{Experimental method}

\subsection{Experimental apparatus}

The measurement of the heat and mass transfer performances of falling films was carried out in the experimental apparatus shown in Fig.1. It consists of a liquid circulation system, vapor condensation system, heating steam system and heat transfer tube in a test section, auxiliary heater device and associated instruments for temperature, pressure and flow rate. The working fluid is pumped by pump 3 from the 
metering tank 2 to the top reservoir 6 . Here the fluid is heated by the auxiliary heater 1 to a certain temperature, then it passes through a regulating valve 4 and flows into the flow meter 5 , and the fluid is from the flow meter 5 to the top reservoir 6 at a desired flow rate. Finally, the falling films is formed on the inner surface of the studied heat transfer tube. The top of the heat transfer tube has a flow development section of $0.2 \mathrm{~m}$, which ensures that the liquid films is flowing evenly before heating, and their actual effective heated lengths are all $2.3 \mathrm{~m}$. Before the experiments, the heat transfer tubes were first washed with acid solution and then with alkaline solution, and finally with water to eliminate the fouling of the wall surface and make the surface clean. The geometry parameters of the studied heat transfer tubes are listed in Tab.1 and the structural scheme of the CD tube is illustrated in Fig.2. Evaporated vapor from the liquid films is collected into the condensers 13 and 14 , and the condensate liquids is sent back to the metering tank 18 for measurement. The unevaporated liquids entered metering tank 12. The outside of the heat transfer tube is supplied with saturated heating steam. Before the experiment begins, valves 19 and 20 are opened, the air outside the heat transfer tube is discharged by saturated heating steam. In the experiment, the valve 20 is closed and the valve 19 is adjusted slightly so that the saturated heating steam outside of heat transfer tube is maintained at a constant temperature and pressure. Steam condensation generated during the experiment is sent to the metering tank 11 through the vapor-liquid separator 9.

Temperature (liquid, heating steam), mass (liquid, vapor), volume flow rate, and heating steam pressure were measured by platinum resistance temperature sensors with an accuracy of $\pm 0.1^{\circ} \mathrm{C}$ at the full scale $\left(-50-180^{\circ} \mathrm{C}\right)$ produced in Shanghai Jiamin Instrument Co., Ltd., China, weighing devices with an accuracy of $\pm 1.0 \mathrm{~g}$ at the full scale $(0-50 \mathrm{~kg})$ produced in Ruian Ante Weighing Equipment Co. Ltd., China, a rotameter with an accuracy of $\pm 1.5 \%$ at the full scale $(10-100 \mathrm{~L} / \mathrm{h})$ produced in Jiangsu Zhongnan Instrument Technology Co., Ltd., China and a pressure transmitter with an accuracy of $\pm 0.1 \%$ at the full scale $(0-0.16 \mathrm{MPa})$ produced in Shanghai Yichuan Instrument Factory, China, respectively. Acquisition time for each set of data is about $30 \mathrm{~min}$, timer accurate to $0.1 \mathrm{~s}$. 
In the experiment, the liquid films inside the heat transfer tube should be kept in a stable state with uniform thickness, and flowed down over the circumference of the heat transfer tube. If the heat transfer tube is not at right angle to the horizon or its inlet port is not smooth, the film diffusion will become non-uniform and there may be localized drying-out of the tube wall. Fig. 3 shows the bottom top view of the falling film top reservoir 6 . In the test range, when fluid was pumped into the top reservoir 6 , the water flowed down slowly through the reservoir wall. The water inside the reservoir, via the way of overflow, overflowed from outside of the heat transfer tube, passed through the tube walls, and then flowed down along the inside vertical tube surface in the form of thin falling films. The steady state of the films was decided by whether the water level in the reservoir was constant or not, and that the liquid films flowed down over the circumference of the heat transfer tube was judged by whether the liquid films flowed out over the circumference of the heat transfer tube or not.

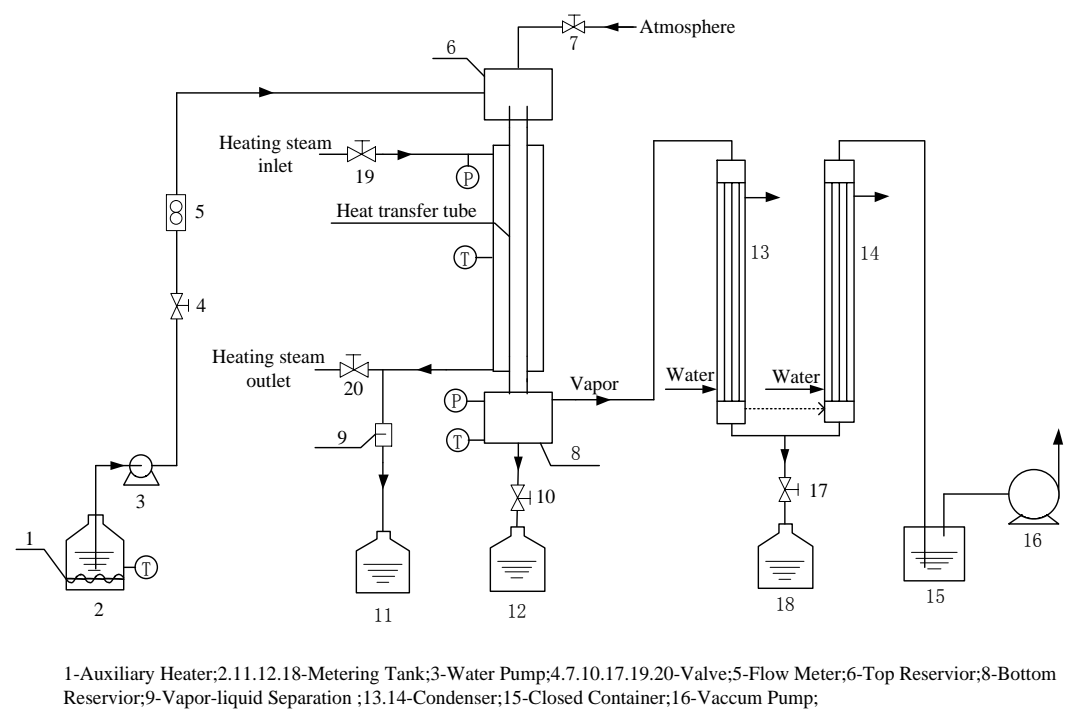

Fig.1 Schematic diagram of the experimental apparatus

Tab.1 Main structure dimension of heat transfer tubes

\begin{tabular}{cccccccc}
\hline Tube type & $d_{\mathrm{o}}(\mathrm{m})$ & $d_{\mathrm{i}}(\mathrm{m})$ & $L(\mathrm{~m})$ & $p(\mathrm{~m})$ & $p_{1}(\mathrm{~m})$ & $p_{2}(\mathrm{~m})$ & $e(\mathrm{~m})$ \\
\hline CD tube 1\# & 0.019 & 0.016 & 2.3 & 0.0115 & 0.0005 & 0.011 & 0.0005 \\
CD tube 2\# & 0.019 & 0.016 & 2.3 & 0.0115 & 0.011 & 0.0005 & 0.0005 \\
CD tube 3\# & 0.019 & 0.016 & 2.3 & 0.014 & 0.0105 & 0.0035 & 0.002 \\
CD tube 4\# & 0.019 & 0.016 & 2.3 & 0.014 & 0.0035 & 0.0105 & 0.002 \\
Smooth tube & 0.019 & 0.017 & 2.3 & & & & \\
$d_{\mathrm{o}}=$ outer diameter; $d_{\mathrm{i}}=$ inner diameter; $L=$ length of analysis segment; $p=$ pitch spacing; \\
$p_{1}=$ length of converging segment; $p_{2}=$ length of diverging segment; $e=$ rib height. \\
\hline
\end{tabular}




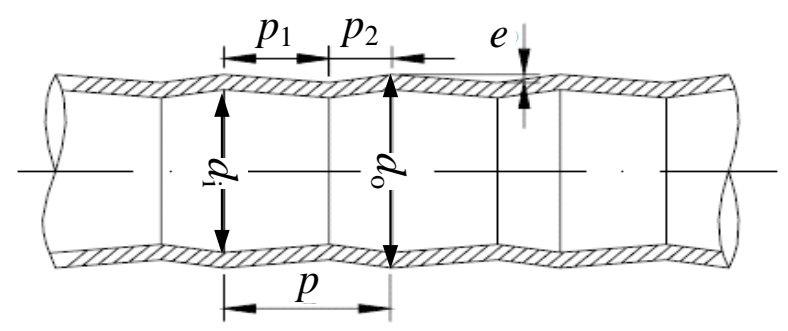

Fig.2 Structural scheme of converging-diverging tubes

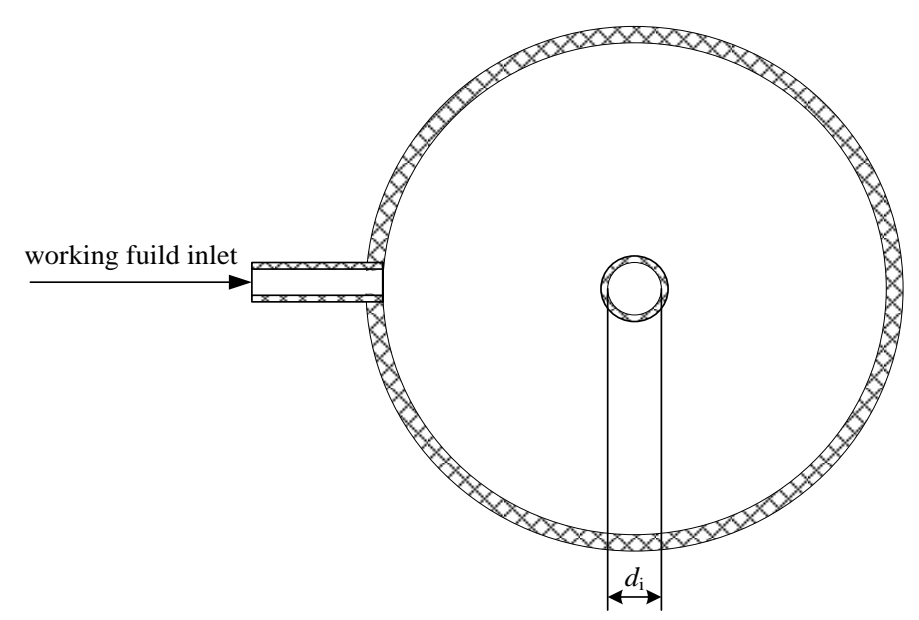

Fig.3 Bottom top view of falling film top reservoir

\subsection{Experimental procedure}

When the heating steam outside the heat transfer tube is maintained at $100{ }^{\circ} \mathrm{C}$, the medium (water) at atmospheric temperature flows into the heat transfer tube. Then the first falling film experiment is performed at different water flow rates. The fluid is heated to the boiling point and evaporation begins. The entire process within the heat transfer tube is divided into a sensible heating stage and an evaporation stage. Then the second falling film experiment is repeated by preheating the water to the boiling point again. This time, there is only one evaporation stage for the entire process. The heat transfer process of the falling films in the heat transfer tube is showed in Fig.4. 


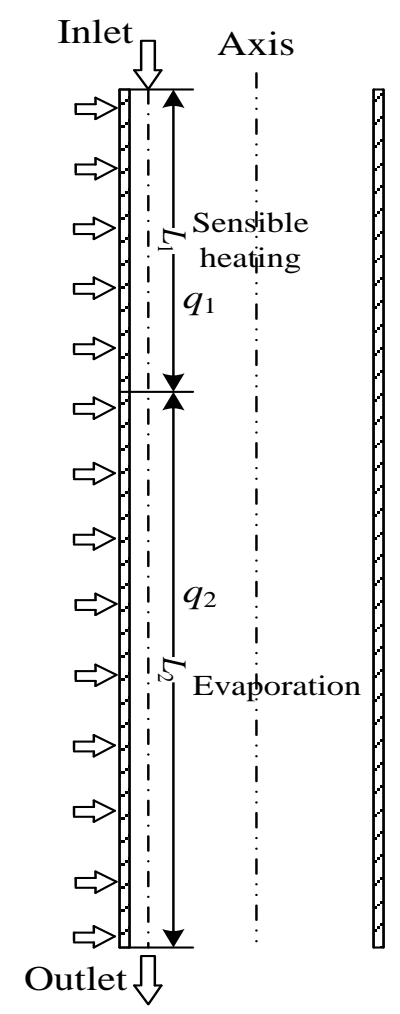

Fig.4 Scheme of the falling films within the heat transfer tube

\subsection{Data reduction}

In each heat transfer experiment, the difference between "the mass of falling films entering the heat transfer tube" and "the mass of falling films flowing out and evaporating" is kept within $\pm 3 \%$. The difference between "the heat released from the heating steam condensation outside the heat transfer tube" and "the heat absorbed by the falling films inside the heat transfer tube" is kept within $\pm 8 \%$. The accuracy of all experimental data was ensured according to the mass and energy balance of the fluid.

In the first falling film experiment, each falling film heating process was divided into two segments: falling film sensible heating and falling film evaporation. The heat flux density of the first segment $\left(q_{1}\right)$ and second segment $\left(q_{2}\right)$ were respectively:

$$
\begin{aligned}
& q_{1}=\frac{c_{p} m_{l}\left(T_{\text {in }}-T_{\text {out }}\right)}{\pi d_{i} L_{1} t} \\
& q_{2}=\frac{r m_{v}}{\pi d_{i} L_{2} t} \\
& L_{1}+L_{2}=L
\end{aligned}
$$

where $c_{p}$ is the specific heat capacity of liquid film, $\mathrm{J} /(\mathrm{kg} \cdot \mathrm{K}) ; m_{l}$ is the mass of liquid films, $\mathrm{kg} ; T_{\mathrm{in}}$ is the liquid film inlet temperature of the first section, $\mathrm{K} ; T_{\text {out }}$ 
is the liquid film outlet temperature of the first segment or evaporation temperature of the second segment, $\mathrm{K} ; d_{i}$ is the inner diameter of heat transfer tube, $\mathrm{m} ; L_{1}$ is the length of the first segment, $\mathrm{m} ; t$ is the experimental run time, $\mathrm{s} ; r$ is the vaporization latent heat of liquid film under saturation temperature, $\mathrm{J} / \mathrm{kg} ; m_{v}$ is the mass of liquid film evaporation, $\mathrm{kg} ; L_{2}$ is the length of the second segment, $\mathrm{m} ; L$ is the length of analysis segment of the heat transfer tube.

The overall heat transfer coefficients of the falling film sensible heating $\left(K_{1}\right)$ and falling film evaporation $\left(K_{2}\right)$ were:

$$
\begin{aligned}
& K_{1}=\frac{q_{1}}{\Delta T_{\mathrm{LMTD}}} \\
& K_{2}=\frac{q_{2}}{T_{k}-T_{\text {out }}}
\end{aligned}
$$

where $T_{k}$ is the heating steam temperature outside the heat transfer tube, $\mathrm{K} ; \Delta T_{\mathrm{LMTD}}$ is the logarithmic mean temperature difference, defined as:

$$
\Delta T_{\mathrm{LMTD}}=\frac{\left(T_{k}-T_{\text {in }}\right)-\left(T_{k}-T_{\text {out }}\right)}{\ln \left(\left(T_{k}-T_{\text {in }}\right) /\left(T_{k}-T_{\text {out }}\right)\right)}
$$

The heat transfer coefficient of the falling film sensible heating or falling film evaporation $(h)$ was:

$$
h=\frac{d_{o}}{d_{i}} \cdot \frac{1}{\left(\frac{1}{K}-\frac{1}{h_{o}}-\frac{d_{o}}{2 \lambda_{S}} \ln \frac{d_{o}}{d_{i}}\right)}
$$

where $d_{o}$ is the outer diameter of the heat transfer tube, $m ; \lambda_{\mathrm{s}}$ is the thermal conductivity coefficient of the heat transfer tube, $\mathrm{W} /(\mathrm{m} \cdot \mathrm{K}) ; h_{o}$ is the heating steam condensation heat transfer coefficient outside the heat transfer tube.

The heating steam condensation heat transfer coefficient $\left(h_{o}\right)$ outside the heat transfer tube was computed by Nusselt's filmwise condensation experimental correlation. When deducing the theoretical equation to calculate the average $h_{o}$ of laminar filmwise condensation, Nusselt proposed a series of assumptions that may not completely hold in real applications. In fact, the majority of experimental results were about $20 \%$ larger than the theoretical calculations. Thus, we adopted a modified equation [35-36]:

$$
h_{o}=1.13\left[\frac{r_{0} \rho_{0}^{2} g \lambda_{0}^{3}}{\mu_{0} L\left(T_{k}-T_{o}\right)}\right]^{1 / 4}=1.76 \lambda_{0}\left(\frac{\rho_{0}^{2} g}{\mu_{0}^{2}}\right)^{1 / 3} R_{0}{ }^{-1 / 3}
$$

where $r_{0}$ is the condensation latent heat of heat transfer tubers under saturated 
vapors, $\mathrm{J} / \mathrm{kg} ; \rho_{0}$ is the density of condensation liquid, $\mathrm{kg} / \mathrm{m}^{3} ; g$ is the acceleration of gravity, $\mathrm{m} / \mathrm{s}^{2} ; \lambda_{0}$ is the thermal conductivity coefficient of condensation liquid, $\mathrm{W} /(\mathrm{m} \cdot \mathrm{K}) ; \mu_{0}$ is the dynamic viscosity of condensation liquid, $\mathrm{kg} /(\mathrm{m} \cdot \mathrm{s}) ; T_{o}$ is the outer wall temperature of tubes, $\mathrm{K} ; R e_{0}$ is the Reynolds number of condensation liquid.

In the second falling film evaporation experiments, with Eqs. (2), (5), (7) and (8), we got the correlativity between the evaporation heat transfer coefficients and falling film flow rate inside the heat transfer tubes. According to the average liquid film Reynolds number in the second section of the first falling film experiments, and through the correlativity between the evaporation heat transfer coefficients and falling film flow rate inside the heat transfer tubes, we got the heat transfer coefficient of the second section through interpolation. With Eqs. (2), (5), (7) and (8), we calculated the length of the second segment $\left(\mathrm{L}_{2}\right)$, and the length of the first segment $\left(L_{1}\right)$ can be determined.

The dimensionless heat transfer coefficients of the first segment or second segment $\left(h^{+}\right)$was:

$$
h^{+}=h\left(\frac{v^{2}}{g \lambda^{3}}\right)^{1 / 3}
$$

where $v$ is the dynamic viscosity of liquid films, $\mathrm{m}^{2} / \mathrm{s} ; \lambda$ is thermal conductivity coefficient of liquid films, $\mathrm{W} /(\mathrm{m} \cdot \mathrm{K})$.

The average perimeter flow rates of the first segment or second segment $(\Gamma)$ was:

$$
\Gamma=\frac{\mathrm{m}_{l}}{\pi d_{i} t}
$$

The average Reynolds numbers of the first segment or second segment $(R e)$ was:

$$
R e=\frac{4 \Gamma}{\mu}
$$

where $\mu$ is the dynamic viscosity of liquid films, $\mathrm{kg} /(\mathrm{m} \cdot \mathrm{s})$.

The average liquid film evaporation mass transfer rate $\left(u_{v}\right)$ was:

$$
u_{v}=\frac{m_{v}}{\pi d_{i} L_{2} t}
$$




\subsection{Error analysis}

Except for mass, temperature and experiment time of falling liquid films that were measured instrumentally, other parameters defined in this study (e.g. Reynolds number, overall heat transfer coefficients of the falling film evaporation and sensible heating, evaporation and sensible heating heat transfer coefficients inside heat transfer tubes and evaporation mass flow rate of falling films) were determined from experimental data. Generally, the uncertainty resulting from instruments and fluctuations of experimental conditions can be analyzed. In order to well present the error analysis, we summarized the mean relative errors of key parameters in Table 2. The principle of uncertainty propagation was applied to each experimental data point [37]. Thus, the relative errors of the parameters to be calculated were computed as follows:

$$
\begin{aligned}
& \frac{\delta R e}{R e}=\left[\left(\frac{\delta m_{l}}{m_{l}}\right)^{2}+\left(\frac{\delta t}{t}\right)^{2}\right]^{\frac{1}{2}} \\
& \frac{\delta K}{K}=\left[\left(\frac{\delta q}{q}\right)^{2}+\left(\frac{\delta T_{k}}{T_{k}-T}\right)^{2}+\left(\frac{\delta T}{T_{k}-T}\right)^{2}\right]^{\frac{1}{2}} \\
& \frac{\delta h}{h}=h\left[\left(\frac{d_{i}}{d_{o}} \cdot \frac{\delta K}{K} \cdot \frac{1}{K}\right)^{2}+\left(\frac{d_{i}}{d_{o}} \cdot \frac{\delta h_{0}}{h_{0}} \cdot \frac{1}{h_{0}}\right)^{2}\right]^{\frac{1}{2}} \\
& \frac{\delta u_{v}}{u_{v}}=\left[\left(\frac{\delta m_{v}}{m_{v}}\right)^{2}+\left(\frac{\delta t}{t}\right)^{2}\right]^{\frac{1}{2}}
\end{aligned}
$$

where the influence of some parameters such as the tube dimensions and geometrical properties of the experimental setup are of minor importance, because of the accurate measurements. Further, the heating steam condensation heat transfer coefficient outside the heat transfer tube is calculated by the modified Nusselt's film condensation relation, and the error of the relation is ignored.

The mean relative errors for Reynolds number, overall heat transfer coefficient, evaporation heat transfer coefficient and evaporation mass flow rate of falling films are $2.5 \%, 3.4 \%, 7.5 \%, 2.5 \%$ for the falling film evaporation experiments within the $\mathrm{CD}$ tubes, and $2.5 \%, 3.4 \%, 6.6 \%, 2.5 \%$ for smooth tube, respectively. The mean relative errors for Reynolds number, overall heat transfer coefficient, sensible heating 
heat transfer coefficient are $2.5 \%, 2.6 \%, 6.1 \%$ for the falling film sensible heating experiments within the $\mathrm{CD}$ tubes, and $2.5 \%, 2.6 \%, 5.3 \%$ for smooth tube, respectively.

Table 2 Parameters and estimated uncertainties

\begin{tabular}{|c|c|c|}
\hline Parameters & Symbols (Unit) & Uncertainty \\
\hline \multirow{2}{*}{ Mass } & $m_{v}(\mathrm{~g})$ & $\pm 1.0 \mathrm{~g}$ \\
\hline & $m_{l}(\mathrm{~g})$ & $\pm 1.0 \mathrm{~g}$ \\
\hline \multirow{2}{*}{ Temperature } & $T_{k}\left({ }^{\circ} \mathrm{C}\right)$ & $\pm 0.1^{\circ} \mathrm{C}$ \\
\hline & $T\left({ }^{\circ} \mathrm{C}\right)$ & $\pm 0.1^{\circ} \mathrm{C}$ \\
\hline Time & $t(\mathrm{~s})$ & $\pm 0.1 \mathrm{~s}$ \\
\hline \multicolumn{3}{|l|}{ For the $\mathrm{CD}$ tubes (falling film evaporation) } \\
\hline Reynolds number & - & $2.5 \%$ \\
\hline Overall heat transfer coefficient & $K\left(\mathrm{~W} /\left(\mathrm{m}^{2} \cdot{ }^{\circ} \mathrm{C}\right)\right)$ & $3.4 \%$ \\
\hline Evaporation heat transfer coefficient & $h\left(\mathrm{~W} /\left(\mathrm{m}^{2} \cdot{ }^{\circ} \mathrm{C}\right)\right)$ & $7.5 \%$ \\
\hline Evaporation mass flow rate & $u_{v}\left(\mathrm{~kg} /\left(\mathrm{m}^{2} \cdot \mathrm{s}\right)\right)$ & $2.5 \%$ \\
\hline \multicolumn{3}{|c|}{ For the $\mathrm{CD}$ tubes (falling film sensible heating) } \\
\hline Reynolds number & - & $2.5 \%$ \\
\hline Overall heat transfer coefficient & $K\left(\mathrm{~W} /\left(\mathrm{m}^{2} \cdot{ }^{\circ} \mathrm{C}\right)\right)$ & $2.6 \%$ \\
\hline Sensible heating heat transfer coefficient & $h\left(\mathrm{~W} /\left(\mathrm{m}^{2} \cdot{ }^{\circ} \mathrm{C}\right)\right)$ & $6.1 \%$ \\
\hline \multicolumn{3}{|c|}{ For the smooth tube (falling film evaporation) } \\
\hline Reynolds number & - & $2.5 \%$ \\
\hline Overall heat transfer coefficient & $K\left(\mathrm{~W} /\left(\mathrm{m}^{2} \cdot{ }^{\circ} \mathrm{C}\right)\right)$ & $3.4 \%$ \\
\hline Evaporation heat transfer coefficient & $h\left(\mathrm{~W} /\left(\mathrm{m}^{2} \cdot{ }^{\circ} \mathrm{C}\right)\right)$ & $6.6 \%$ \\
\hline Evaporation mass flow rate & $u_{v}\left(\mathrm{~kg} /\left(\mathrm{m}^{2} \cdot \mathrm{s}\right)\right)$ & $2.5 \%$ \\
\hline \multicolumn{3}{|c|}{ For the smooth tube (falling film sensible heating) } \\
\hline Reynolds number & - & $2.5 \%$ \\
\hline Overall heat transfer coefficient & $K\left(\mathrm{~W} /\left(\mathrm{m}^{2} \cdot{ }^{\circ} \mathrm{C}\right)\right)$ & $2.6 \%$ \\
\hline Sensible heating heat transfer coefficient & $h\left(\mathrm{~W} /\left(\mathrm{m}^{2} \cdot{ }^{\circ} \mathrm{C}\right)\right)$ & $5.3 \%$ \\
\hline
\end{tabular}




\section{Results and discussion}

\subsection{Falling film evaporation heat transfer coefficient}

Fig.5 shows the effect of liquid film Reynolds number on the evaporation heat transfer coefficient for the four CD tubes and the smooth tube. We know that studies of falling film evaporation in vertical smooth tubes have been conducted by a number of researchers, The Chun and Seban's correlation was considered more accurate by the sixth International Heat Transfer Conference [38], and widely used in falling film evaporation. We also experimentally analyzed falling film evaporation in vertical smooth tube, compared the results with calculations of the Chun and Seban's correlation, and the largest error is within $\pm 6 \%$. For a comparison of experimental results with literature data, it is important to ensure that the experimental system and experimental data of falling film evaporation are modestly reliable and accurate. As shown in Fig.5, with the increase of $R e$, the evaporation heat transfer coefficient of the smooth tube declines, which is consistent with Chun and Seban [1] who reported the liquid film evaporation heat transfer under a similar range of Reynolds number. This is mainly because the increase of liquid film flow rate leads to the enlargement of film thickness, and despite the large or small waves atop the liquid films, it helps to enhance heat transfer. Nevertheless, the unfavorable factors still surpass the favorable factors, leading to a reduction in the evaporation heat transfer coefficient. With the $R e$ rises from 1000 to 2600 , the falling film evaporation heat transfer coefficients of CD tubes all increase. The evaporation heat transfer coefficients of $\mathrm{CD}$ tubes are all smaller than the smooth tube when $R e$ is 1000 to 1500 , but are larger when $R e$ is 1500 to 2600. It is indicated the CD tubes are appropriate for falling film evaporation with large liquid film Reynolds number, while the smooth tube is better in case of small $R e$. This is because at small $R e$, film thickness dominates the evaporation heat transfer coefficients of falling films. In the CD tubes, the alternate arrangement of converging segment and diverging segment leads to the periodical " increase and decrease " of film thickness in the falling film process, but the average film thickness is larger than the constant film thickness of the smooth tube, so the heat transfer effect is reduced. 
As the $R e$ rises, the liquid films in the $\mathrm{CD}$ tubes become more turbulent, so the turbulent-induced heat transfer is more influential than film thickness and the falling film evaporation heat transfer coefficient gradually increases. As for different dimensions, the falling film evaporation heat transfer coefficients of CD tubes $3 \#$ and 4\# both are better than tubes 1\# or 2\#. This is because tubes $3 \#$ and $4 \#$ have larger rib heights, which appropriately help to efficiently induce the disturbance of liquid films [32]. In the meantime, the falling film evaporation heat transfer coefficients of $\mathrm{CD}$ tubes $3 \#$ and $2 \#$ are better than tubes $4 \#$ and 1\#, respectively. This is mainly because the heat transfer performance is enhanced in the converging segment and weakened in the diverging segment, according to the field synergy theory. Thus, at the same rib height and rib pitch, the longer the converging segment of the CD tube is, the better the heat transfer performance is [29-30].According to the comparative analysis of the evaporation heat transfer performances inside the four $\mathrm{CD}$ tubes, the $\mathrm{CD}$ tube $3 \#$ is best. At Reynolds number of 2356, the evaporation heat transfer coefficient of tube $3 \#$ is $62 \%$ higher than the smooth tube.

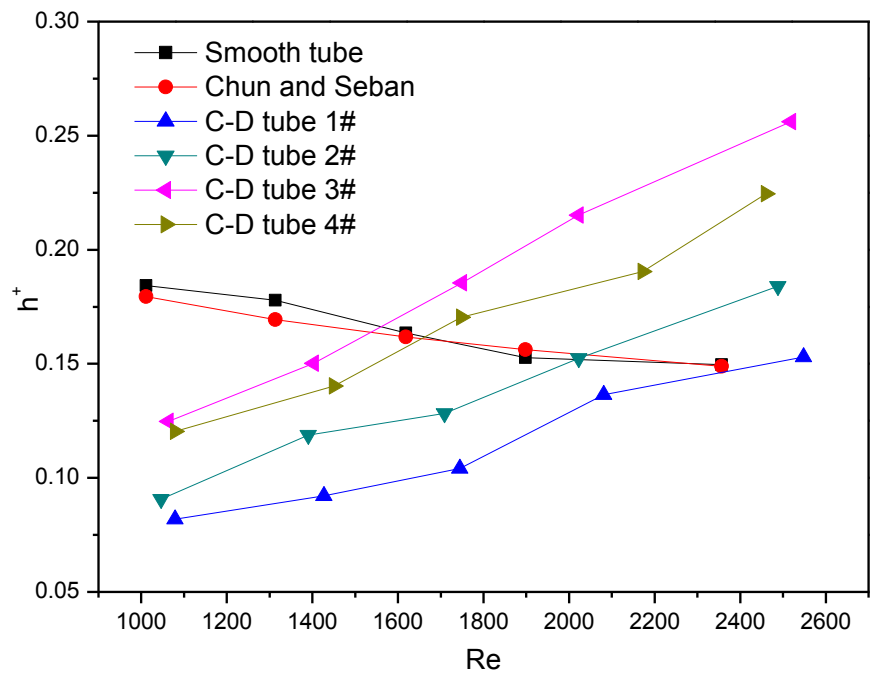

Fig.5 Effect of liquid film Reynolds number on the evaporation heat transfer coefficient

\subsection{Falling film evaporation mass transfer}

The effect of perimeter flow rate on the evaporation mass transfer rate for the four $\mathrm{CD}$ tubes and the smooth tube is illustrated in Fig.6. When the perimeter flow 
rate increased, the evaporation mass transfer rates rose in the $\mathrm{CD}$ tubes and decreased in the smooth tube. The reason is that a larger evaporation heat transfer coefficient promotes the heat absorption by the liquid films, leading to the increasing of evaporation in the liquid films and thus the evaporation mass transfer rate. Moreover, with the rise of flow rate, the evaporation mass transfer rates of tubes $3 \#$ and $4 \#$ both surpass that of tube $1 \#, 2 \#$ or the smooth tube, and tubes $3 \#$ and $2 \#$ are better than tubes $4 \#$ and $1 \#$, respectively. When the perimeter flow rate of liquid films is 0.173 $\mathrm{kgm}^{-1} \mathrm{~s}^{-1}$, the evaporation mass transfer rate of falling films in tube $3 \#$ is 0.0094 $\mathrm{kgm}^{-2} \mathrm{~s}^{-1}$, which is $38 \%$ significantly higher than the smooth tube.

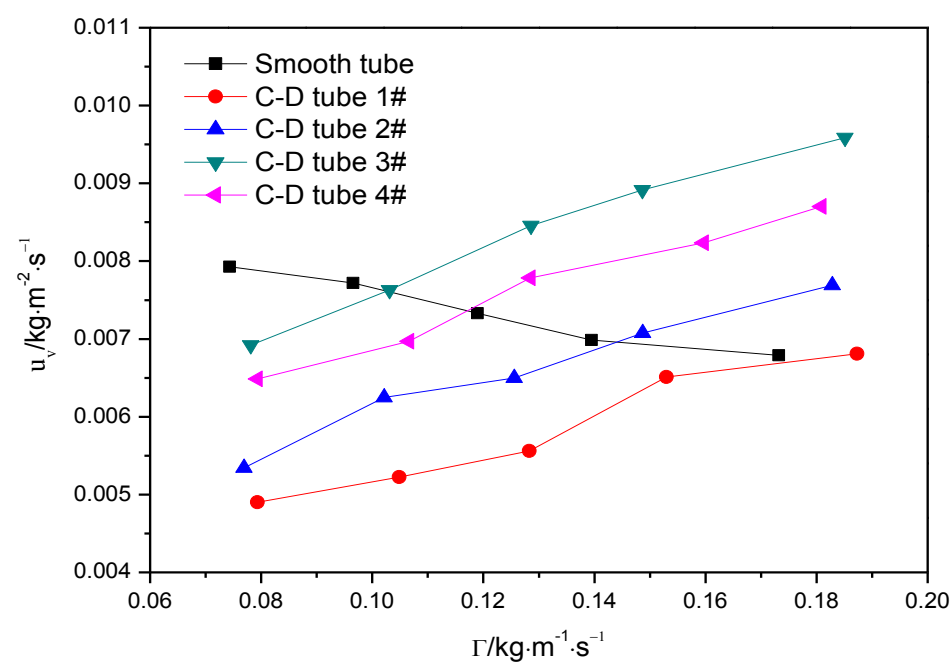

Fig.6 Effect of liquid film perimeter flow rate on the evaporation mass transfer rate

\subsection{Falling film sensible heating heat transfer coefficient}

The effect of liquid film Reynolds number on the sensible heating heat transfer coefficient for the four CD tubes and the smooth tube is illustrated in Fig.7. Much work has been done in the past in the field of falling film sensible heating in vertical smooth tube. In particular, Wilke's [39] empirical formula was widely used in falling film sensible heating. We also experimentally analyzed sensible heating in vertical smooth tube and compared the results with calculations of the Wilke's empirical formula, and the largest error was below $\pm 5 \%$. Generally, it is believed the 
experimental data of falling film sensible heating was accurate. With the Reynolds number rises, the falling film sensible heating coefficients of $C D$ tubes all increase. The sensible heating heat transfer coefficients of CD tubes are all smaller than the smooth tube when $R e$ is 700 to 1200 , but are larger when $R e$ is 1200 to 1700 . It is indicated the $\mathrm{CD}$ tubes are appropriate for falling film sensible heating with large $R e$, while the smooth tube is better in case of small $R e$. This is because for small $R e$, the film thickness plays a dominant role in the sensible heating heat transfer coefficients of falling films. The CD tube has an alternate converging and diverging segment, which leads to the periodical "increase and decrease" of film thickness during the falling film process, and the average film thickness is larger than the smooth tube with constant film thickness, so the heat transfer effect is weakened. As the Re increases, the turbulent of liquid films in the $\mathrm{CD}$ tubes is intensified, so the heating heat transfer coefficient of falling films increases. Comparison between Figs.5 and 7 suggests the CD tubes showed similar rules during the falling film evaporation and sensible heating. The falling film sensible heating heat transfer coefficients of CD tubes $3 \#$ and $4 \#$ both are better than tubes $1 \#$ and $2 \#$, and tubes $3 \#$ and $2 \#$ are better than tubes $4 \#$ and 1\#, respectively. Likewise, structure parameters of the $\mathrm{CD}$ tubes have great influence on sensible heating heat transfer coefficient. According to the comparative analysis of the sensible heating heat transfer performances inside the four CD tubes, the CD tube $3 \#$ is best. At Reynolds number of 1635, the sensible heating heat transfer coefficient of tube $3 \#$ is $63 \%$ higher than the smooth tube. 


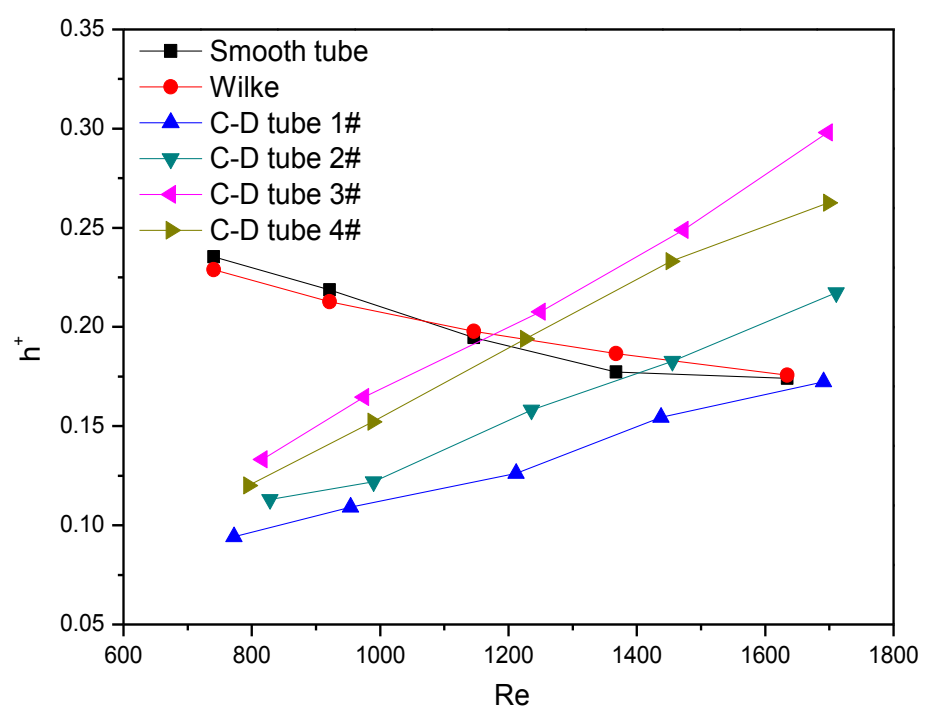

Fig.7 Effects of liquid film Reynolds number on the sensible heating heat transfer coefficient

\subsection{Heat transfer between the sensible heating segment and evaporation segment of falling films in the same tube}

When the falling films at normal temperature entered the heat transfer tubes, the comparisons of the sensible heating and evaporation heat transfer coefficients of falling films in CD tubes 1\#, 2\#, 3\# and 4\# are illustrated in Figs.8-11, respectively. In the same tube, the evaporation and sensible heating heat transfer coefficients both increase with the rise of falling film flow rate, and the former is larger. Within the experimental range, the evaporation heat transfer coefficients of tubes $1 \#, 2 \#, 3 \#$ and $4 \#$ are $70.6 \%, 87.0 \%, 32.6 \%$ and $29.7 \%$ larger than the corresponding sensible heating heat transfer coefficients, respectively. 


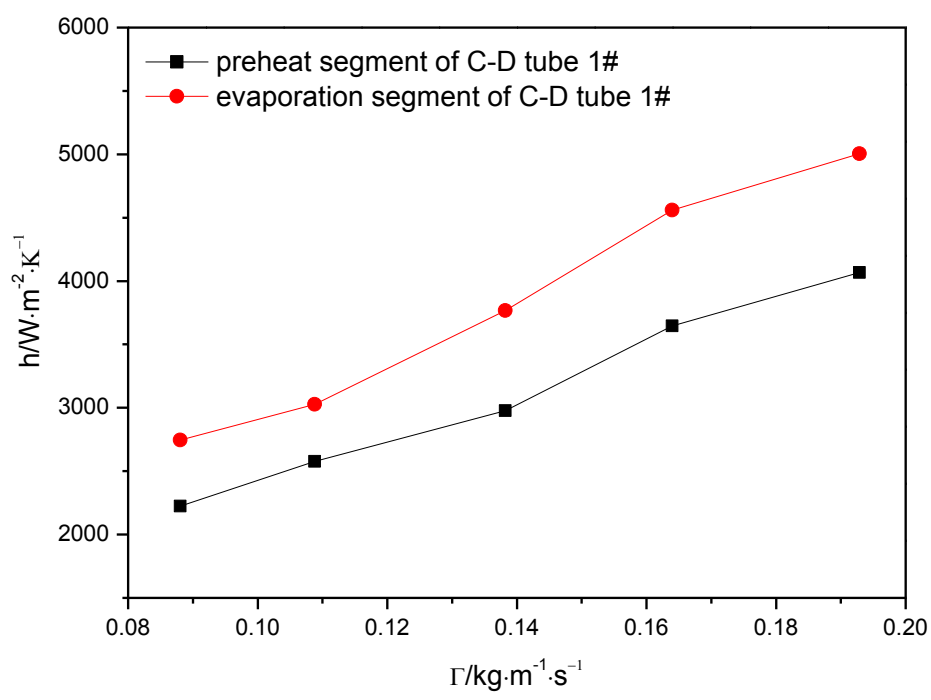

Fig.8 Comparison of sensible heating and evaporation heat transfer coefficients within the tube 1\#

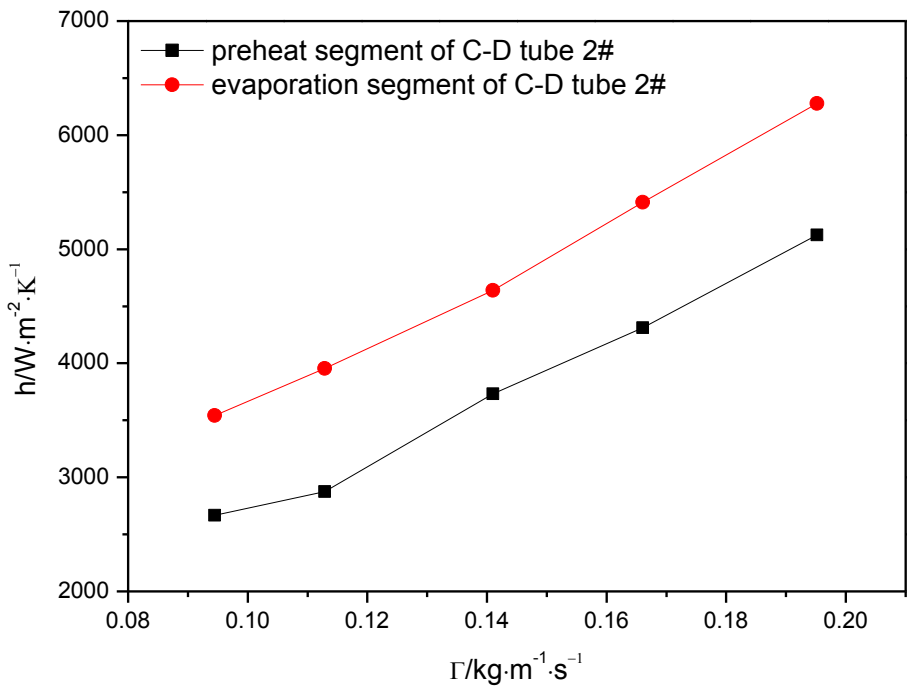

Fig.9 Comparison of sensible heating and evaporation heat transfer coefficients within the tube 2\# 


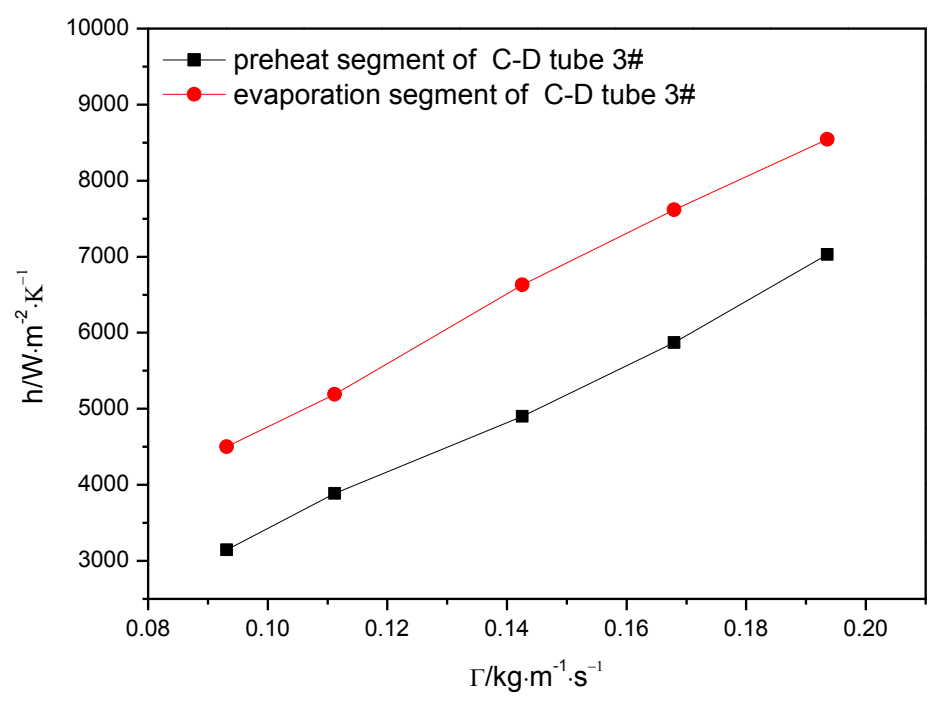

Fig.10 Comparison of sensible heating and evaporation heat transfer coefficients within the tube 3\#

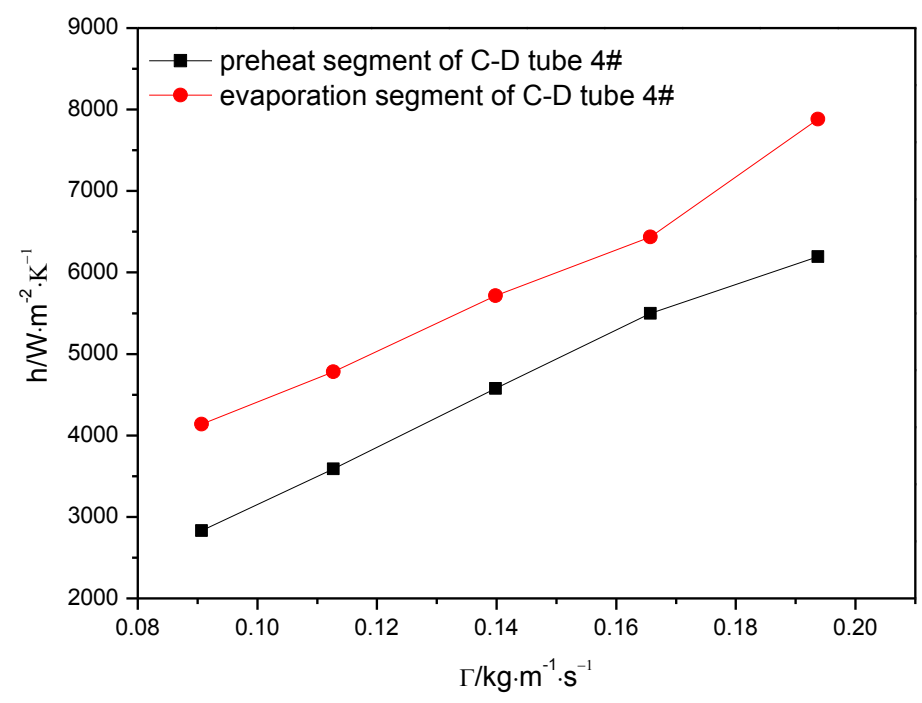

Fig.11 Comparison of sensible heating and evaporation heat transfer coefficients within the tube $4 \#$

\subsection{Heat transfer correlations derived from experimental data}

As indicated above analysis of experimental results, the falling film evaporative heating and sensible heating within the $\mathrm{CD}$ tubes are very complicated due to the multitude of influencing factors. Structure parameters of the CD tubes have great 
influence on heat transfer coefficient. In this study, dimensionless parameters $p / d_{\mathrm{i}}$ 、 $p_{1} / p_{2}, e / d_{\mathrm{i}}$ are used to describe the configuration of the $\mathrm{CD}$ tubes. For engineering propose, we try to model $h$ in function of important influencing parameters only. By using the dimensional analysis technique and the regression method, we obtain the correlations for the Nusselt numbers of falling film evaporative heating and sensible heating within the $\mathrm{CD}$ tubes as follows:

For the falling film evaporative heating

$h^{+}=7.565 \times 10^{-4}\left(p / d_{\mathrm{i}}\right)^{1.58837}\left(p_{1} / p_{2}\right)^{0.03835}\left(e / d_{\mathrm{i}}\right)^{0.20337} \operatorname{Re}^{0.80716} \operatorname{Pr}^{1 / 3}$

For the falling film sensible heating

$h^{+}=2.247 \times 10^{-4}\left(p / d_{\mathrm{i}}\right)^{1.6}\left(p_{1} / p_{2}\right)^{0.03267}\left(e / d_{\mathrm{i}}\right)^{0.25} \operatorname{Re}^{1.00787} \operatorname{Pr}^{1 / 3}$

The validity of using Eqs.17-18 to predict the experimental heat transfer coefficients is shown in Figs.12, respectively. As shown in Fig.12(a), for the correlation on the heat transfer coefficients of the falling film evaporative heating within the CD tubes, all the experimental data fall within $\pm 20 \%$ error of the calculated values from the correlation equation. The maximum error between computation and experiments is $19.4 \%$. Meanwhile, as shown in Fig.12(b), for the correlation on the heat transfer coefficients of sensible heating within the $\mathrm{CD}$ tubes, all the experimental data fall within $\pm 10 \%$ error of the calculated values from the correlation equation. The maximum error between computation and experiments is 9.0\%. Overall, good agreement has been observed between experimental data and theoretical prediction. 


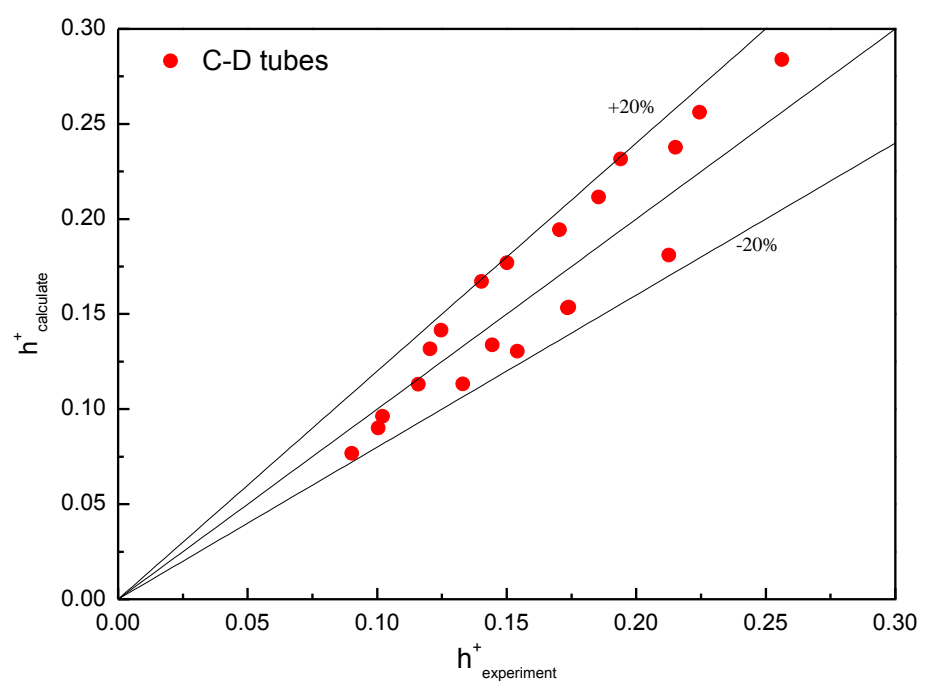

(a) evaporation heat transfer coefficients

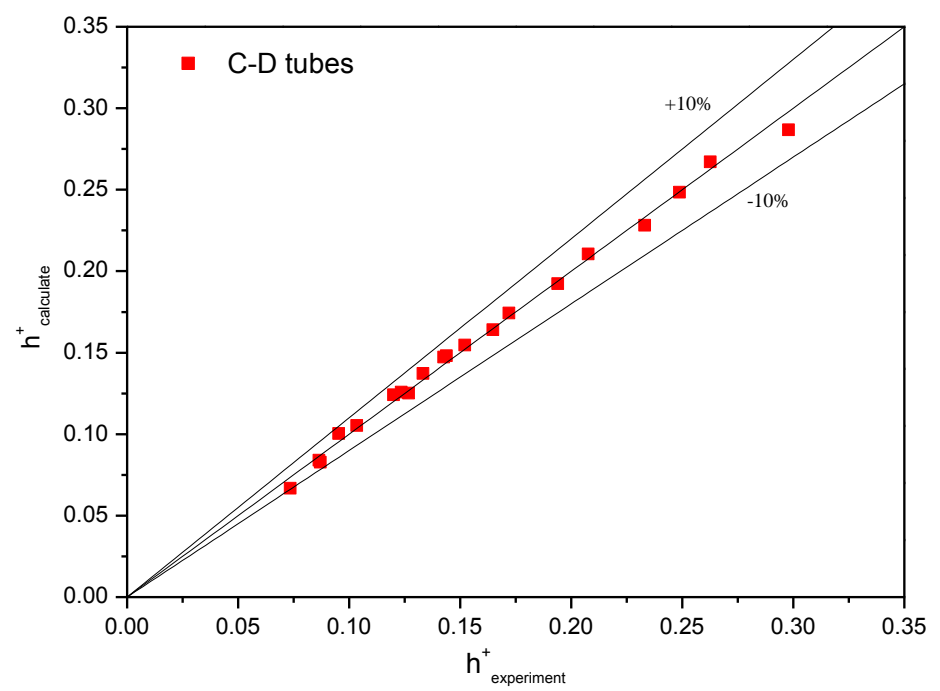

(b) heat transfer coefficients of sensible heating

Fig.12 Comparison of the experimental data of the $\mathrm{CD}$ tubes versus the calculated values.

\section{Conclusions}

To improve the heat and mass transfer performances of falling films and develop a new type of falling film evaporator, here we first used CD tube to falling film evaporation, and experimentally characterized the heat and mass transfer of falling film evaporation and sensible heating within four CD tubes with different dimensions, and compared them with a smooth tube. It was found CD tubes were appropriate for 
falling film evaporation and sensible heating with large liquid film Reynolds number. As for different dimensions, the key factor affecting the evaporation and sensible heating heat transfer of falling films was the rib height. At the same rib height and rib pitch, the longer the converging segment of the $\mathrm{CD}$ tube was, the better the heat transfer performance was. According to the comparative analysis of the evaporation and sensible heating heat transfer performances inside the four $\mathrm{CD}$ tubes, the $\mathrm{CD}$ tube 3\# is best. The evaporation heat transfer coefficient (at Reynolds number of liquid films of 2356), evaporation mass transfer rate (at the perimeter flow rate of liquid films is $0.173 \mathrm{kgm}^{-1} \mathrm{~s}^{-1}$ ), and sensible heating heat transfer coefficient (at Reynolds number of liquid films of 1635 ) of $\mathrm{CD}$ tube $3 \#$ are $62 \%, 38 \%$ and $63 \%$ higher than that of the smooth tube, respectively. Therefore, CD tube exhibits better heat and mass transfer performances of falling films. For the same CD tube, the evaporation heat transfer coefficient is larger than the sensible heating heat transfer coefficient, but both increased with the rise of flow rate. Moreover, the correlations of the evaporation and sensible heating heat transfer coefficients of falling films were obtained. Using CD channel is a suitable method to improve the heat and mass transfer performances of falling films, and this study provides a novel clue for developing a new type of falling film evaporator.

\section{Author information}

\section{Corresponding Author}

*Telephone/Fax: +86-020-62874844. E-mail: huangkuo2006@126.com.

\section{Conflicts of interest}

The authors declare no competing financial interest.

\section{Acknowledgements}

The authors would like to thank team members for their contributions, and key laboratory of enhanced heat transfer and energy conservation of the State Education 
Ministry, South China University of Technology for providing the test rig and test device.

\section{Nomenclature}

$c_{p}$ Specific heat capacity of liquid film, $\mathrm{J} /(\mathrm{kg} \cdot \mathrm{K})$

$d_{o}$ Outer diameter of the heat transfer tube, $\mathrm{m}$

$d_{i}$ Inner diameter of the heat transfer tube, $\mathrm{m}$

$g$ Acceleration of gravity, $\mathrm{m} / \mathrm{s}^{2}$

$h$ Falling film sensible heating or evaporation heat transfer coefficient inside of the heat transfer tube, $\mathrm{W} /\left(\mathrm{m}^{2} \cdot \mathrm{K}\right)$

$h^{+}$Dimensionless falling film sensible heating or evaporation heat transfer coefficient inside the heat transfer tube

$h_{o}$ Heating steam condensation heat transfer coefficient outside the heat transfer tube, $\mathrm{W} /\left(\mathrm{m}^{2} \cdot \mathrm{K}\right)$

$K$ Overall sensible heating or evaporation heat transfer coefficient of falling films, $\mathrm{W} /\left(\mathrm{m}^{2} \cdot \mathrm{K}\right)$

$L \quad$ Valid height of the heat transfer tube, $\mathrm{m}$

$m_{l} \quad$ Mass of liquid films, $\mathrm{kg}$

$m_{v} \quad$ Mass of liquid film evaporation, $\mathrm{kg}$

$q$ Heat flux density of falling film sensible heating or evaporation, $\mathrm{W} / \mathrm{m}^{2}$

$r$ Vaporization latent heat of liquid films under saturation temperature, $\mathrm{J} / \mathrm{kg}$

$r_{0}$ Condensation latent heat of heat transfer tube under saturated vapor, $\mathrm{J} / \mathrm{kg}$

$R e_{0}$ Reynolds number of condensation liquids

$R e \quad$ Average Reynolds number of liquid films

$T_{o} \quad$ Outer wall temperature of tube, $\mathrm{K}$

$\Delta T_{\mathrm{LMTD}}$ Logarithmic mean temperature difference, $\mathrm{K}$

$T_{k} \quad$ Heating steam temperature outside the heat transfer tube, $\mathrm{K}$

$T \quad$ Temperature of liquid films, $\mathrm{K}$

$t$ Experimental time, $\mathrm{s}$

$u_{v}$ Liquid film evaporation mass transfer rate, $\mathrm{kg} /\left(\mathrm{m}^{2} \cdot \mathrm{s}\right)$ 


\section{Greek Symbols}

$\Gamma \quad$ Liquid film perimeter flow rate inside heat transfer tube, $\mathrm{kg} /(\mathrm{m} \cdot \mathrm{s})$

$\lambda_{0}$ Thermal conductivity coefficient of condensation liquids, $\mathrm{W} /(\mathrm{m} \cdot \mathrm{K})$

$\lambda_{s}$ Thermal conductivity coefficient of heat transfer tube, $\mathrm{W} /(\mathrm{m} \cdot \mathrm{K})$

$\lambda$ Thermal conductivity coefficient of liquid films, $\mathrm{W} /(\mathrm{m} \cdot \mathrm{K})$

$\mu \quad$ Dynamic viscosity of liquid films, $\mathrm{kg} /(\mathrm{m} \cdot \mathrm{s})$

$\mu_{0} \quad$ Dynamic viscosity of condensation liquids, $\mathrm{kg} /(\mathrm{m} \cdot \mathrm{s})$

$v$ Dynamic viscosity of liquid films, $\mathrm{m}^{2} / \mathrm{s}$

$\pi \quad$ Constant, 3.1415926

$\rho_{0} \quad$ Density of condensation liquids, $\mathrm{kg} / \mathrm{m}^{3}$

\section{Subscripts}

$1=$ sensible heating

2 = evaporative heating

$\mathrm{i}=$ inside of tube

$l=$ liquid

$\mathrm{o}=$ outside of tube

$\mathrm{v}=$ vapor

\section{References}

[1] J.Y.Zhang, B.X.Wang, X.F.Peng, Falling liquid film thickness measurement by an optical-electronic method, Review of Scientific Instruments 71 (4) (2000) 1883-1886. [2] K.R. Chun, R.A.Seban, Heat transfer to evaporating liquid films, J. Heat Transfer Trans. ASME 3 (1971) 391-396.

[3] S. Ishigai, S. Nakanisi, T. Koizumi, Z. Oyabu, Hydrodynamics and heat transfer of vertical falling films (part 1, classification of flow regimes), Bull. JSME 15 (83) (1972) 594-602.

[4] A. Alhusseini, K. Tuzla, J. Chen, Falling film evaporation of single component liquids, Int. J. Heat Mass Transfer 41 (12) (1998) 1623-1632.

[5] N.M.A1-Najem, K.Y. Ezuddin, M.A. Darwish, Heat transfer analysis of preheated 
turbulent falling films in vertical tube evaporators, Desalination 115 (1998) 43-55. [6] J.S.Prost, M.T. González, M.J.Urbicain, Determination and correlation of heat transfer coefficients in a falling film evaporator, Journal of Food Engineering 73 (2006) 320-326.

[7] F.Weise, S. Scholl, Evaporation of pure liquids with increased viscosity in a falling film evaporator, Heat Mass Transf. 45 (2007) 1037-1046.

[8] M. Härkönen. Heat transfer to evaporating falling films of water and sugar/water solution, Heat and mass transfer, 29 (1994) 349-353.

[9] R.Krupiczka, A.Rotkegel, Z.Ziobrowski, Heat transfer to evaporating liquid films within a vertical tube, Chemical Engineering and Processing 41 (2002) 23-28.

[10] Y.L.Cheng, X.M.Ye, W.P.Yan, Effect of nonlinear surface tension on heat transfer stability in saturated liquid film, Journal of North China Electric Power University 29 (2002) 50-53.

[11] S.M.Yih, J.L.Liu, Prediction of heat transfer in turbulent falling liquid films with or without interfacial shear, AIChE Journal 29 (1983) 903-909.

[12] T. Storch, C. Philipp, A. Doeg, U.Gross, Near-zero shear stress experiments with heat flux effects on falling film evaporation inside a vertical tube, Int. J. Therm. Sci. 76 (2014) 137-146.

[13] U.Gross, Ch.Philipp, Conjugated shear stress and Prandtl number effects on reflux condensation heat transfer inside a vertical tube, Int. J. Heat Mass Transf. 49 (2006) 144-153.

[14] V.V. Lel, G.F. Dietze, H. Stadler, F. Al-Sibai, R. Kneer, Investigation of the thermal entry length in laminar wavy falling films, Microgravity Sci. Technol. 19 (3/4) (2007) 66-68.

[15] E. Chinnov, S. Abdurakipov, Thermal entry length in falling liquid films at high Reynolds numbers, Int. J. Heat Mass Transfer 56 (2013) 775-786

[16] VDI-Wärmeatlas, Verein Deutscher Ingenieure, 9th edn. Springer-Verlag, Heidelberg, 2002[17] N.E.Fagerholm, A.R.Ghazanfari, K.Kivioja, Boiling heat transfer performance of plain and porous tubes in falling film flow of refrigerant R114, Heat and Mass Transfer, 21(6) (1987) 343-353. 
[18] I.S. Park, D.H. Choi. Heat and mass transfer analysic for the condensing film flow along a vertical grooved tube. International Journal of Heat and Mass transfer. 44 (2001) 4277-4285.

[19] S.N.Jiang, Study on the characteristic of heat transfer and hydrodynamics of falling film evaporation in a vertical wavy wall tube, $\mathrm{PhD}$, Tianjin University of Science and Technology, 2004.

[20] H.Pehlivan, Experimental investigation of convection heat transfer in converging-diverging wall channels, International Journal of Heat and Mass Transfer 66 (2013) 128-138.

[21] A.Gonda, P.Lancereau, P.Bandelier, L.Luo , Y. Fan, S.Benezech, Water falling film evaporation on a corrugated plate, International Journal of Thermal Sciences 81 (2014) 29-37.

[22]Y.J.Fan, H.Xu, P.Xu, Heat transfer experiment of falling-film evaporation in vertical porous tube, CIESC Journal 67(2) (2016)512-518.

[23] X.H.Deng, S.Z.Ye, The application of new-type heat exchanger in sulfuric acid conversion systems, Journal of sulphuric acid industry 10 (6) (1996) 19-23.

[24]G.Z.Xu,Approach to construction scheme of Jingcang Smelters newsulphuric acid system, Sulphuric Acid Industry 18 (3) (2004) 23-27.

[25] M.A. Habib, I.UL-Haq, H.M.Badr, et al., Calculation of turbulent flow and heat transfer in periodically converging-diverging channel, Computers and Fluids 27(1) (1998) 95-120.

[26] X.H.Deng, W.J.Huang, Constrction and application of gas heat exchanger with sharp expansion and accelerated flow converging-diverging tubes, Sulphuric acid industry, 5 (2005) 22-24.[27] Y.J.Zhang, O.Y.Rong, X.H.Deng, Z.W.Li, Natural convection heat transfer in diverging-converging tube and developed diverging-converging tube, Chemical Equipment Technology 26 (1) (2005) 32-35.

[28] Y.J.Zhang, O.Y.Rong, X.H.Deng, Z.W.Li, Natural Convection Boiling Heat Transfer in Enhanced Heat Transfer Tubes. Journal of South China University of Technology (Natural Science Edition) 32 (1) (2004) 41-48.

[29] Y.Chen, X.H.Deng, X.J.Ding, Convection heat transfer of converging-diverging 
tube (I) mechanism of field synergy principle, Journal of Chemical Industry and Engineering (China) 55 (11) (2004) 1759-1763.

[30] Y.Chen, X.H.Deng, X.J.Ding, Convection heat transfer of converging-diverging tube (II) optimal geometry configuration, Journal of Chemical Industry and Engineering (China) 55 (11) (2004) 1764-1767.

[31] Z.H. Lin, Augmentation Heat Transfer and Industrial Application, China Machine Press, 1987:32-35.[32] W.J. Huang, X.H. Deng, S.H. Zhou, Mechanism of heat transfer enhancement for converging-diverging tube, Fluid machinery 36 (12) (2005) 54-58.

[33] W.J. Huang, X.H. Deng, M.N. Hong, et al., Optimization of heat transfer and rib height definition for air flowing in a converging-diverging tube, Petroleum Processing and Petrochemicals 36 (12) (2005) 54-58.

[34] V.S. Duryodhan, A.Singh, S.G. Singh, A.Agrawal, Convective heat transfer in diverging and converging microchannels, International Journal of Heat and Mass Transfer 80 (2015) 424-438.

[35] S.W.Qian, Heat exchanger design manual, Chemical Industry Press, 2002.

[36] Y.Y.Yao, C.G.Chen, C.J.Chai, The principles of chemical engineering (second edition). Tianjin: Tianjin University Press, 2004.

[37] J.R.Taylor, An Introduction to error analysis-the study of uncertainties in physical measurements. University Science Books, California.1982.

[38] R.A.Seban, Proc.6th Int. Heat Transfer Conf. 6 (1978) 417-418.

[39]W.Wilke,Wärmeübergang an rieselfilme,VDI Forschungsh 490 (1962)1-36. 